\title{
Moral Theory and Theorizing in Healthcare Ethics
}

\author{
Mike McNamee • Thomas Schramme
}

Published online: 27 May 2011

(C) Springer Science+Business Media B.V. 2011

Written nearly a quarter of a century apart, the musings of Stephen Toulmin and Glenn McGee might be seen as scholarly bookends. Back in 1982, Toulmin (1982) penned a widely cited article "How medicine saved the life of ethics". The success or otherwise of medical ethics led McGee (2006), another leading American scholar, to write an Editorial in 2006 asking "Will bioethics take the life of philosophy?".

The papers collated for this special issue seek to address an aspect of the problematic issues Toulmin and McGee raise. They stem from the first workshop in a series of three, held in Swansea (UK), of a Research Network on "The Role of Moral Theory in Health Care Ethics", funded by the Arts and Humanities Research Council, UK. The initial stimulus for the research project was caused mainly by several concerns regarding the current state of applied ethics in general, and health care ethics ${ }^{1}$ in particular: Firstly, the increasing professionalization of applied ethics, especially in the field of medical ethics, which seems to lead to naivety and carelessness about the many abstract and theoretical problems that underlie moral issues. Secondly, the question what the proper role of philosophers might be in "doing" applied ethics is far from clear. Thirdly, despite professional developments in the field (perhaps, indeed because of them) there is a lack of proper or agreed upon methods of doing applied ethics generally and healthcare ethics in particular. These issues bear down upon the more pressing and more general problem of how we may go about justifying normative claims. These issues are not peculiar to applied ethics. Rather, they relate to ethics in general. It was a core goal of the project to investigate the relations between moral theory and health care ethics. Nevertheless, in order to do

\footnotetext{
${ }^{1}$ Health care ethics is the name given to the broader field of which medical ethics is a part. It is taken to cover, among other things, nursing ethics. Medical ethics, as the name suggests, relates ethical thinking to the more restricted sphere of medicine.

M. McNamee $(\bowtie)$

College of Human and Health Sciences, Swansea SA28PP, UK

e-mail: m.j.mcnamee@swansea.ac.uk

T. Schramme $(\bowtie)$

Universität Hamburg, Philosophisches Seminar, Von-Melle-Park 6, 20146 Hamburg, Germany

e-mail: Thomas.Schramme@uni-hamburg.de
} 
applied ethics properly, we need to take moral theory into account, if only to be sensitised to its peculiarities and shortcomings.

But it is not enough to reflect on the methodology, or methodologies, of health care ethics, and to explore what the role of moral theory might be in deliberating about ethical issues; we also need a clear grasp of how health care ethics is actually being carried out (or "performed" as some might put it), because only then we can understand the real and potential problems of putting ethics into practice. How ethics is done is an empirical matter. It was therefore vital for our project to include sociologists; researchers who study the discourse of health care ethics as well as the operation of organisations involving ethical expertise, such as clinical ethics committees. In that sense, the scope of the present essays, though bearing directly upon McGee and Toulmin's musings, are intentionally broader in scope.

A good example of the methodological quandaries of healthcare ethics is the habitual reference to "reflective equilibrium" as a method of justification, which can be found in numerous textbooks and other publications in applied ethics. Indeed, as John D. Arras has recently put it: "In the world of bioethics, the air is abuzz with reflective equilibrium." (Arras 2007: 46) Reflective equilibrium is supposed to be reached by striking a balance between considered moral judgements, moral principles, and so-called background theories. It seems that this model, which is far from being precisely articulated (and, at least for many scholars, far from convincing), has become the magic bullet for silencing the nagging fear that we actually might not have any convincing model when it comes to justifying normative claims. It is true, of course, that reflective equilibrium was introduced in order to establish a coherentist, in contrast to a foundational, model of normative justification, which has been out of fashion for some time. Yet despite the wide scale abandoning of the search for an Archimedean point in ethics, it seems reasonable to demand a little more than the vague coherentism promised by reflective equilibrium. For instance, what is the exact role of the "independent" (Daniels 1979) element of wide reflective equilibrium, i.e. background theories? Do these lead us back to a foundationalist methodology after all?

The embarrassing lack of an agreed proper method puts ethicists, especially moral philosophers, in an awkward position when it comes to addressing concrete and pressing problems in applied ethics. Few people would expect ethicists to actually solve these problems. Nevertheless it is thought by some-in the mode of the now outdated engineering model of applied ethics, where moral judgements are deduced from an already established normative theory - that ethicists should at least come up with something approaching convincing support for particular moral claims, even though the actual decision might then be taken by, say, committee decision or democratic vote. But moral philosophers not only lack a consensus about normative beliefs and about theories supporting particular moral beliefs; they even lack a shared methodology as to how to assess those theories. This scarcely qualifies them as essential members of ethics committees, where a consensus, and not further dust-raising, is the overarching aim.

How should we deal with this situation? Does it mean that moral theory should be abandoned and that philosophers should give up on doing applied ethics? This would certainly not be a reasonable response. A more adequate reaction would be to reconsider the role of moral theory in applied ethics, to renegotiate its function in justifying moral beliefs and to rethink methodological aspects of moral philosophy in relation to practical moral problems. This rejuvenated interest in moral theory in relation to applied ethics might eventually even result in a more convincing account of reflective equilibrium that has been criticised before.

Yet the concept of moral theory is itself somehow ambiguous. Presumably the first notion a philosopher might think of are normative theories such as consequentialism, 
deontology or (despite its looser systematization) virtue ethics. Moral theories, according to this understanding, are primarily systems of moral principles which are supported by particular reasons, which allegedly justify these principles. One might wonder what the role of these theories is when we do applied ethics. It is now widely assumed that we cannot simply apply those theories to moral problems that we encounter in diverse contexts, such as medicine, like mechanics who applies their tools to the repair of a car. Moreover, the term 'moral theory' might also refer to an analysis of theoretical problems in moral philosophy, for instance of methods of justification or of the possibility of moral knowledge. This way of doing moral theory, or theorizing about moral issues, might or might not lead to particular commitments in terms of normative theories. Developing a moral theory in the first sense is certainly different from doing moral theory or theorizing in the second sense of the term. So even if we eschew normative theory in applied ethics, we might nevertheless need moral theory in the second sense of the term. Given that moral theorizing is a proper and traditional task for philosophers, perhaps not everything is lost for them with respect to contributing to applied ethics.

Bearing in mind the distinction between normative moral theories and theorizing about ethical issues, the papers presented here set out to explore two main issues: Firstly, whether there is a proper role in health care ethics for either normative moral theory or for moral theorizing? This question, again, can be tackled from two different perspectives, a normative or philosophical and a descriptive or sociological perspective. The normative aspect of the question considers whether there is a point in using moral theory, either normative theory or ethical analysis, to frame and solve moral problems, hence what should be the role of moral theory in healthcare ethics. The empirical aspect of the question addresses whether healthcare practitioners actually use moral theories, or whether they theorize about moral issues, hence what in actual fact is the role of moral theory in doing healthcare ethics. Secondly, the essays aim at an assessment of particular elements of moral theory and their role in doing health care ethics, for instance, what method or methods does moral theory need?; what is the function of empirical findings?; can a care ethics perspective avoid the problems of normative theory like utilitarianism or Kantianism when it comes to health care ethics? or, finally, is coherence of normative beliefs enough to justify certain moral beliefs?

The authors within this issues wrestle with distinct but related problems within the above constellation of issues. Tom Sorrel defends the significance of moral philosophy for health care ethics and criticizes the "blinkered" approach of principlism by focusing on the recent debate on telecare. Although principlism can play a useful role within health care ethics, its limitations need to be rectified by moral theory. Alan Cribb is concerned with the relation of the theorist as an expert in moral theory and the practitioner. Although he also defends the significance of theory in doing applied ethics, he points out the need to theorize without losing sight of the practical problems. Torbjörn Tannsjö) defends a more straightforward role of moral theory, which might lead to practical solutions by applying justified moral principles. He defends the guidance function of normative theory against challenges by intuitionism and particularism. Joan Tronto addresses political dimensions of doing ethics and thereby undermines the confidence in using moral philosophy as a neutral tool to practical problems. She flags up the relational aspect of claims to authority, which is often found in health care ethics. Raymond de Vries adds a sociological perspective on the way health care ethics is often carried out. He points out serious detriments that might be caused by moral theory and moral philosophers when practical clinical issues need (often swift) decisive action. Finally, Hugh Upton's essay is a summative one that calls for an agnosticistic approach to the question of the proper role for moral theory in health care 
ethics. He carefully considers the traditional contours of normative theories and shows that their relevance for solving practical issues in health care is not decisive. Nevertheless, he argues, they can systematically enhance our appreciation of the problems at hand.

The symposium, which provided the opportunity for discussing the issues developed in this brief introduction, was merely one of many springboards into the family of issues raised between applied and theoretical ethics. Far from representing the beginning of the debate about the methodology of applied ethics, they offer further and specific avenues to the discussion started by Toulmin nearly 30 years ago regarding this problematic relation.

Acknowledgements We express our thanks to co-organisers of the symposia: Andrew Bloodworth; Zuzana Deans, Andrew Edgar, Steven Edwards, Oskar MacGregor, Søren Holm, Ruud ter Meulen, Ainsley Newson, and Hugh Upton. Moreover, we express our appreciation to the Arts and Humanities Research Council (grant no: AH/G019207/1)

\section{References}

Arras JD (2007) The way we reason now: reflective equilibrium in bioethics. In: Steinbock B (ed) Oxford handbook of bioethics. Oxford University Press, Oxford, pp 46-71

Daniels N (1979) Wide reflective equilibrium and theory acceptance in ethics. J Philos; LXXVI:5:256-282.

McGee G (2006) Will bioethics take the life of philosophy? Am J Bioeth 6(5):1-2

Toulmin S (1982) How medicine saved the life of ethics. Perspect Biol Med 25(4):736-750 